\title{
IMOGEN: an intermediate complexity model to evaluate terrestrial impacts of a changing climate
}

\author{
C. Huntingford ${ }^{1}$, B. B. B. Booth ${ }^{2}$, S. Sitch ${ }^{3, *}$, N. Gedney ${ }^{3}$, J. A. Lowe ${ }^{4}$, S. K. Liddicoat ${ }^{2}$, L. M. Mercado ${ }^{1}$, M. J. Best ${ }^{3}$,

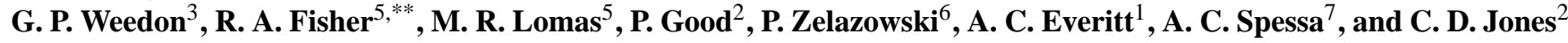 \\ ${ }^{1}$ Centre for Ecology and Hydrology, Wallingford, OXON, OX10 8BB, UK \\ ${ }^{2}$ Met Office Hadley Centre, Fitz Roy Road, Exeter, Devon, EX1 3PB, UK \\ ${ }^{3}$ Joint Centre for Hydro-Meteorological Research, Met Office Hadley Centre, Wallingford, OXON, OX10 8BB, UK \\ ${ }^{4}$ Reading Unit, Met Office Hadley Centre, Department of Meteorology, University of Reading, Earley Gate, P.O. Box 243, \\ Reading, RG6 6BB, UK \\ ${ }^{5}$ Department of Animal and Plant Sciences, University of Sheffield, Western Bank, Sheffield, S10 2TN, UK \\ ${ }^{6}$ Environmental Change Institute, School of Geography and the Environment, Oxford, OX1 3QY, UK \\ ${ }^{7}$ National Centre for Atmospheric Sciences, Department of Meteorology, University of Reading, Earley Gate, P.O. Box 243, \\ Reading, RG6 6BB, UK \\ *now at: School of Geography, University of Leeds, Leeds, LS2 9JT, UK \\ ** now at: Earth and Environmental Sciences, Los Alamos National Laboratory, Los Alamos, New Mexico, NM 87545, USA
}

Received: 6 July 2010 - Published in Geosci. Model Dev. Discuss.: 4 August 2010

Revised: 5 November 2010 - Accepted: 9 November 2010 - Published: 29 November 2010

\begin{abstract}
We present a computationally efficient modelling system, IMOGEN, designed to undertake global and regional assessment of climate change impacts on the physical and biogeochemical behaviour of the land surface. A patternscaling approach to climate change drives a gridded land surface and vegetation model MOSES/TRIFFID. The structure allows extrapolation of General Circulation Model (GCM) simulations to different future pathways of greenhouse gases, including rapid first-order assessments of how the land surface and associated biogeochemical cycles might change. Evaluation of how new terrestrial process understanding influences such predictions can also be made with relative ease.
\end{abstract}

\section{Introduction}

General Circulation Models (GCMs) remain the main tool of climate change research and it is predominantly these models that led the latest Intergovernmental Panel on Climate Change (IPCC) report (IPCC, 2007) to conclude that recent increases in global average temperatures are "very likely"

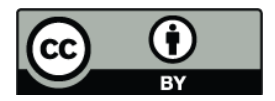

Correspondence to: C. Huntingford (chg@ceh.ac.uk) due to increased greenhouse gas concentrations. Further, for the SRES family of scenarios (Nakiæenoviæ et al., 2000) depicting a range of economic "story-lines" which contain no explicit mitigation policies for emissions (i.e. "business-asusual"), global temperature rise to 2100 is estimated to be in the range $1.1 \mathrm{~K}$ to $6.4 \mathrm{~K}$ above 1990 s levels (IPCC, 2007, Table SPM.3). Even temperature changes towards the lower end of this range will represent significant alterations to the climate system, and are expected to have major local impacts. Aside from a general average increase in temperature, global warming is expected to alter cloud cover, rainfall distribution and intensity, humidity levels and surface winds. Some regions are predicted to warm much faster than others. Although GCMs provide remarkable and important insights in to the functioning of the climate system, they are by necessity highly complex pieces of software. Hence significant time is required to adjust them as new process knowledge becomes available. They are also, computationally, extremely expensive and so it is not always possible to determine quickly climate change impacts associated with any emissions profiles that emerge from policy (e.g. profiles of Moss et al., 2010, or quantifying the effect on climate of the emissions pledges following the 2009 Copenhagen Climate Change conference). A transient GCM simulation, representing a modelled period between the start of the industrial revolution

Published by Copernicus Publications on behalf of the European Geosciences Union. 
and present, and then for a prescribed emissions scenario onwards to year 2100 , will typically require 3 months of computing time to complete. This is in addition to the often considerable time required to spinup the GCM to a pre-industrial state.

The land surface is an integral component of the Earth System, including land-atmosphere exchanges of carbon dioxide, $\mathrm{CO}_{2}$. Such exchanges have a major influence on emission reductions needed to avoid dangerous climate change. The state of the land surface, which itself is affected by climate change (along with other pollutants such as ozone and various land use practises), also has a direct bearing on societal well-being by providing the majority of our food, and influencing water supply and other ecosystem services (e.g. Imhoff et al., 2004; Schröter et al., 2005; Sitch et al., 2007). The potential impact of climate change on agricultural yields is an issue starting to receive particular scrutiny (e.g. Lobell et al., 2007). Altered atmospheric aerosols influence the land surface both through climate change and adjusted ratios of surface direct-to-diffuse radiation (Mercado et al., 2009). For all these reasons, it is important to have a well developed regional description of the land surface and vegetation that captures its expected response to the non-stationary aspects of weather in a changing climate.

The Met Office Hadley Centre land surface model, used in the various configurations of Version 3 of their GCM, consists of the description of vegetation competition and dynamics by the "Met Office Surface Exchange Scheme" (MOSES; Cox et al., 1998, 1999) and the "Top-down Representation of Interactive Foliage and Flora Including Dynamics" (TRIFFID; Cox, 2001). Cox et al. (2000) describe MOSES combined with the interactive vegetation scheme, TRIFFID, coupled to the Hadley Centre GCM and forced by a business-asusual emissions scenario (IS92a; Houghton et al., 1992). In this fully coupled climate-carbon cycle simulation the land surface was predicted to become a source of carbon dioxide in to the atmosphere by the middle of the 21 st Century. The severity of modelled climate change was sufficient to enhance both plant and soil respiration rates enough to overtake any beneficial effects of extra plant fertilisation in a $\mathrm{CO}_{2}$ enriched environment. This feedback is not, however, realised by all models (Friedlingstein et al., 2006) illustrating the importance to understand more fully the processes involved. Further, which future changes in atmospheric greenhouse gas concentrations would avoid such a positive feedback? It is to address these and many similar types of question associated with future land surface functioning in a changing climate, that a computationally efficient model has been developed. The model presented here incorporates an analogue of the climatic response of the Hadley Centre GCM and also contains the full GCM land surface scheme. Called IMOGEN: "Integrated Model Of Global Effects of climatic aNomalies", it is a new type of intermediate complexity model. For different future pathways in atmospheric greenhouse gas concentrations, it provides a fast representation of the climatic response of a GCM to changing radiative forcing, yet with a more complete treatment of land surface processes directly comparable in complexity to those within GCMs.

The IMOGEN system is designed to operate with a range of $\mathrm{CO}_{2}$ emission or concentration scenarios (plus pathways in non- $\mathrm{CO}_{2}$ atmospheric greenhouse gas concentrations) that have not currently been used to force a GCM, generating regional land surface climate impacts assessments. Land surface models are currently undergoing radical change as new geochemical cycles are introduced, along with more sophisticated descriptions of vegetation competition. IMOGEN also allows for the testing of the effect of enhanced process representation in land surface models within a modelled changing climate. An earlier version was used to evaluate the uncertainty in the future modelled climate-carbon cycle introduced by alternative Dynamic Global Vegetation Models (DGVMs) to TRIFFID (Sitch et al., 2008). This previous study was an evaluation of how uncertainty in land processes actually translates into significant uncertainties in the future projections of the climate-carbon cycle system and changes to biogeography. Given the large geographical variability in ecosystem response, such detailed spatial impacts analysis would not have been possible using a simpler zero-order climate-carbon cycle model (e.g. Jones et al., 2006). A longterm aim is to incorporate aspects of the Ecosystem Demography model (Moorcroft et al., 2001; Fisher et al., 2010) into the IMOGEN structure. Hence, IMOGEN fills a gap between full GCM simulations and more illustrative calculations by very fast global "box" models, thus allowing regional impact assessments. An IMOGEN simulation representing, for instance, years 1860 (pre-industrial) to 2100 can be completed in a couple of days on a fast single processor.

\section{Model components and simulations}

\subsection{IMOGEN overview}

The "GCM analogue model" (Huntingford and Cox, 2000) component of IMOGEN was based on approximately linear relationships, as found in simulations by Version 3 of the Met Office Hadley Centre GCM (HadCM3; Gordon et al., 2000), between local meteorological variations and the amount of global average warming. This is sometimes referred to as "pattern scaling". A simple energy balance model then relates changes in concentrations of atmospheric greenhouse gases to the global mean land temperature response, enabling predictions to be made for new pathways in atmospheric greenhouse gas concentrations, and for which the GCM has not been operated. This component is coupled to the MOSES land surface scheme and the TRIFFID model of vegetation competition and dynamics. This combined model system was originally operated with an emphasis on exploring the potential for vegetation "die-back" across the Amazon rainforest as a response to changing climate (Huntingford et al., 


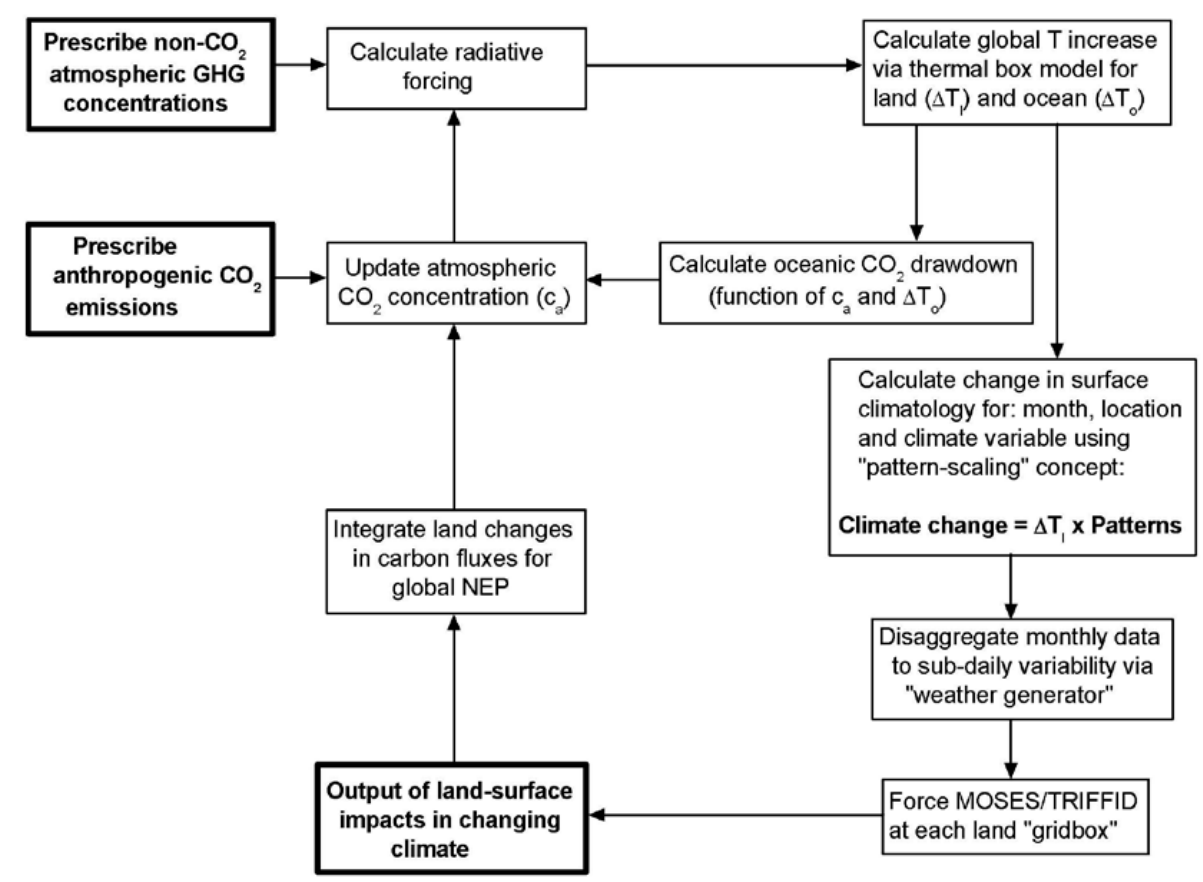

Fig. 1. A schematic of the different components forming the IMOGEN impacts tool. Abbreviations are as follow: GHG for Greenhouse Gases, $T$ for Temperature and NEP for Net Ecosystem Production. Optionally, non- $\mathrm{CO}_{2}$ atmospheric GHG concentrations can be prescribed. Currently IMOGEN excludes the influence on radiation of varying volcanic and non-volcanic aerosols and also varying solar constant.

2004, 2008). Here the complete IMOGEN system available for global impacts modelling is presented.

IMOGEN can operate with a closed global carbon cycle, and thus be forced with $\mathrm{CO}_{2}$ emissions. It can explicitly derive global atmospheric $\mathrm{CO}_{2}$ concentrations at each timestep, modelled as the balance between emissions, areal integration of calculated land-atmospheric fluxes of $\mathrm{CO}_{2}$ and a simple description of global oceanic drawdown of $\mathrm{CO}_{2}$. The resulting changes in atmospheric $\mathrm{CO}_{2}$ concentration feedback on modelled surface climate changes via the energy balance component of the GCM analogue model, and therefore through global land temperature change and regional patterns of climate change. The energy balance component can also account for other climatic drivers, such as non- $\mathrm{CO}_{2}$ greenhouse gases, where the relationship between the drivers and the radiative forcing is known. For example IMOGEN incorporates changes in wetland methane emissions due to climate changes, and how these feedback on atmospheric concentrations and climate (Gedney et al., 2004). A schematic (Fig. 1) shows the linkages between the different parts of the IMOGEN model, as described in more detail below.

\section{2 “GCM analogue model” details}

The GCM that we have attempted to mimic here is HadCM3LC, chosen as this configuration of the Met Office Hadley Centre GCM has nearly identical land surface components to IMOGEN. This version of the GCM has lower ocean resolution ("L") than HadCM3, but a fully interactive carbon cycle ("C"). The actual model simulation by HadCM3LC is similar to that described in Cox et al. (2000), except that here it is forced throughout with the $\mathrm{CO}_{2}$-only component of the historical and SRES A2 future emissions scenario (Nakiæenoviæ et al., 2000). Climatological patterns are found by simple regressions against global land temperature increase, for each variable of interest, for each month and for each grid point, and all for the period 1860 to 2100 . That is, if $\Delta T_{1}(i)(\mathrm{K})$ is the predicted global land temperature increase by year $i$, then change in quantity $V(i, j, k)$ (for month $j$ and spatial position - gridbox $-k$ ) is then approximated as pattern (i.e. regression coefficient) $X_{\mathrm{V}}(j, k)$ multipled by $\Delta T_{1}(i)$. (The fitting is actually made against decadal mean values for each month, position and variable.) The variables for which the patterns are derived are $1.5 \mathrm{~m}$ temperature, $1.5 \mathrm{~m}$ relative humidity, $10 \mathrm{~m}$ wind speed, precipitation, downward shortwave radiation, downward longwave radiation and surface pressure. These are all climatological quantities needed to drive the MOSES/TRIFFID land surface model.

Four parameters are needed for the energy balance model predicting $\Delta T_{1}$, and are derived from GCM diagnostics. These are climate feedback parameters over land and ocean, $\lambda_{1}$ and $\lambda_{\mathrm{o}}\left(\mathrm{Wm}^{-2} \mathrm{~K}^{-1}\right)$ respectively, oceanic "effective thermal diffusivity", $\kappa\left(\mathrm{Wm}^{-1} \mathrm{~K}^{-1}\right)$ representing the ocean thermal inertia and a land-sea temperature contrast parameter, $v$, linearly relating warming over land, $\Delta T_{1}$, to warming 
over ocean, $\Delta T_{\mathrm{o}}(\mathrm{K})$, as $\Delta T_{1}=v \Delta T_{\mathrm{o}}$. The robustness of near-constant land-ocean temperature contrast has been analyzed by Sutton et al. (2007). Climate feedback parameters $\left(\lambda_{1}\right.$ and $\left.\lambda_{0}\right)$ are calibrated using GCM data for top of the atmosphere radiative fluxes, mean land and ocean surface temperatures, along with an estimate of the radiative forcing modelled by the GCM for the $\mathrm{CO}_{2}$ changes (see Sect. 2.3 of Huntingford and Cox, 2000). This optimal fit to the GCM temperature response is referred to as EBM1. However a second configuration generating a land temperature trajectory which was $0.5 \mathrm{~K}$ warmer at 2100 than that modelled by the GCM was also undertaken; referred to as EBM2. The fitting parameters of EBM2 were chosen such that the total terrestrial carbon content in IMOGEN during the latter part of the 21st Century has a good match with that predicted by HadCM3LC. The comparison of the land temperature response $\left(\Delta T_{1}\right)$ with the GCM, for both configurations of the energy balance component, is shown in Fig. 2. For the optimal fit of HadCM3LC in EBM1, it is found that $\lambda_{1}=0.493 \mathrm{Wm}^{-2} \mathrm{~K}^{-1}, \lambda_{\mathrm{o}}=1.581 \mathrm{Wm}^{-2} \mathrm{~K}^{-1}$, $\kappa=367 \mathrm{Wm}^{-1} \mathrm{~K}^{-1}$ and $v=2.02$. The "warmer" fit, EBM2, has values $\lambda_{1}=0.450 \mathrm{Wm}^{-2} \mathrm{~K}^{-1}, \lambda_{\mathrm{o}}=1.460 \mathrm{Wm}^{-2} \mathrm{~K}^{-1}$, but still with $\kappa=367 \mathrm{Wm}^{-1} \mathrm{~K}^{-1}$ and $\nu=2.02$. When we express these parameters in terms of the climate sensitivity, i.e. equilibrium global temperature change for a doubling of $\mathrm{CO}_{2}$, then we obtain values of $3.43 \mathrm{~K}$ for EBM1 and $3.72 \mathrm{~K}$ for EBM2. (As an aside, climate sensitivity is derived from setting $\Delta H_{0}$ to be zero in Eq. (4) of Huntingford and Cox, 2000). Advection $\Delta H_{\mathrm{a}}$ is eliminated between their Eqs. (3) and (4), and then for a radiative forcing $\Delta Q$ for a doubling of atmospheric $\mathrm{CO}_{2}$ concentration, along with their Eq. (9), allows $\Delta T_{1}$ and $\Delta T_{\mathrm{o}}$ to be evaluated. Equilibrium climate sensitivity is given by the calculated global mean temperature increase $(1-f) \Delta T_{1}+f \Delta T_{\mathrm{o}}$ where $f$ is the fraction of Earth covered by ocean.

Calculated mean monthly anomalies in surface climate can be added to either (a) a base climatology, which can be derived from the last years of the "spin-up" phase of a GCM/first years of a transient GCM simulation (and so representing the GCM depiction of a pre-industrial climate) or (b) an averaged period of a climatology based on global measurements (e.g. the Climate Research Unit Global Climate Dataset; see New et al., 1999 and more recent updates). The latter can help to remove any GCM biases in prediction of pre-industrial state. Here, as IMOGEN is presented as emulating HadCM3LC, a base climatology derived from the first decade of the historical simulation (years 1860 to 1869 inclusive) for that model is used. The land surface model in IMOGEN operates at sub-daily timescales (typically hourly) and at present a simple disaggregation scheme is utilised to derive the surface climate ("weather") at those shorter periods. The control climatology includes fields of diurnal temperature range, to which a daily sine wave is fitted, and is then used to perturb the monthly mean calculated temperatures to give diurnal variation. This variation is also used

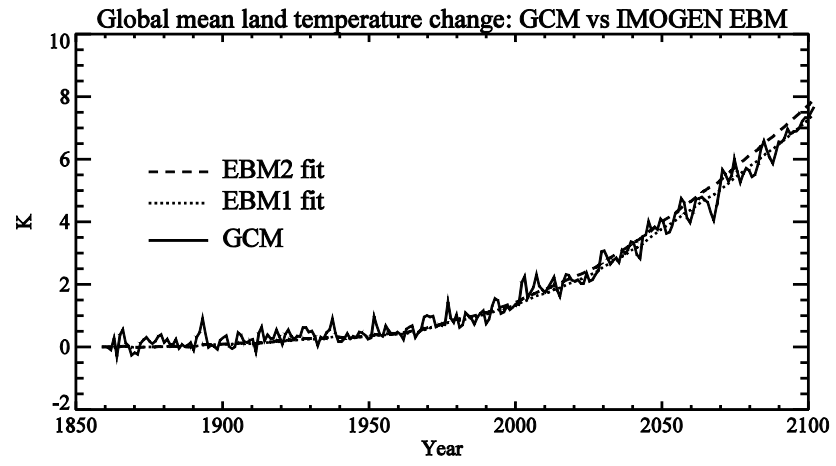

Fig. 2. A comparison of the global mean land temperature response, $\Delta T_{1}$, from 1860 of the two fits of the energy balance component of IMOGEN with the HadCM3LC simulation (continuous line). The EBM1 fit of the energy balance component is shown by the dotted line whilst the EBM2 fit is indicated by the dashed line. The forcing prescribed to the energy balance components of IMOGEN is the $\mathrm{CO}_{2}$ pathway calculated by the HadCM3LC simulation, itself forced with $\mathrm{CO}_{2}$-only component of the SRES A2 emissions profile. The EBM1 fit has an effective climate sensitivity of $3.43 \mathrm{~K}$ and the EBM2 fit of $3.72 \mathrm{~K}$.

to alter the monthly mean downward longwave radiation to sub-daily timescales, through a perturbation to its temperature dependence. Shortwave radiation is altered to include diurnal variation, based on sun angle for day of year, time of day and latitude. The mean monthly precipitation is made to occur for short sub-periods of each day, and a temperature cut-off determines whether it falls as rain or snow.

\subsection{The MOSES and TRIFFID land surface model, and description of the global carbon cycle}

For each IMOGEN grid box, which matches the grid of HadCM3LC down to $60^{\circ} \mathrm{S}$ (thereby ignoring Antarctica) and at sub-daily timesteps, MOSES calculates land-atmosphere fluxes of momentum, heat, vapour and carbon dioxide. There are up to nine possible land surface types within a single gridbox; five Plant Functional Types (PFTs) of broadleaf trees, needleleaf trees, $C_{3}$ grasses, $C_{4}$ grasses and shrubs, and four non-vegetated surface types of urban, inland water, bare soil and ice. The five vegetation surface types are characterized by their albedo, a water-holding capacity, a roughness length and stomatal opening captured through a "stomatal resistance", with the latter dependent on surface conditions. Canopy height, leaf area index and fractional coverage of the five vegetation functional types are provided by the TRIFFID DGVM (this sub-model is called every ten model days). The interaction with TRIFFID is two-way. At ten day timesteps, the mean Net Primary Productivity (NPP) $\left(\mathrm{kg} \mathrm{C} \mathrm{m}^{-2} \mathrm{yr}^{-1}\right.$ ) calculated by MOSES for that period is presented to the TRIFFID model, and based on plant competition rules, new fractional coverages and leaf area indices for the five vegetation types are determined. This will then 
affect estimates of NPP from the beginning of the next 10day timestep. The carbon content for each PFT is a balance between NPP and temperature-dependent plant respiration (Cox, 2001). Soil carbon is represented as a single "box" under all PFTs, and where the carbon content is then a balance between vegetation litterfall and respiration. Soil respiration is modulated by a soil moisture dependence and also a $Q_{10}$ dependence on temperature (again, please see Cox, 2001).

A typical transient simulation by IMOGEN, up to for example year 2100, will be initialized from a year such as 1860 and that is considered representative of the pre-industrial period. Starting the simulation from this year requires an initial state for the vegetation and this is assumed to be in equilibrium with the pre-industrial climate. To achieve this, an initial "spin-up" period by IMOGEN is performed, where the MOSES/TRIFFID model is repeatedly presented with years of forcing climate data representing the initial climate state. The spin-up simulation is sufficiently long (order of a hundred modelled years) that TRIFFID achieves a near equilibrium prediction of coverages by the different biomes.

IMOGEN contains a depiction of the global carbon cycle. This means that carbon dioxide emissions can be prescribed, and atmospheric $\mathrm{CO}_{2}$ concentration is then a model prognostic. At the end of each modelled year, atmospheric carbon dioxide concentration is adjusted for emissions, and then further adjusted based on the global land-atmosphere and ocean-atmosphere fluxes of $\mathrm{CO}_{2}$ for that year (Fig. 1). The land-atmosphere flux is derived, by integrating over all land points for the year, the values of Net Ecosystem Productivity (NEP). This is integrating gridbox mean values of NPP minus soil respiration. The oceanic draw-down is calculated using a single "box" model, as a function of global temperature increase and atmospheric $\mathrm{CO}_{2}$ level (Joos et al., 1996; Appendix of Huntingford et al., 2004). This capability of IMOGEN to model land-surface interactions with the full global carbon cycle allowed estimates to be made of "pay-back" times associated with deliberate planting of energy crops (Hughes et al., 2010). The model can also be forced without an interactive carbon cycle, and instead the atmospheric $\mathrm{CO}_{2}$ concentrations can be prescribed directly. The effect of non- $\mathrm{CO}_{2}$ greenhouse gas concentrations can be prescribed as an additional radiative forcing.

\subsection{A case study}

After the spin-up phase, in the particular simulations presented here, IMOGEN is forced by prescribed $\mathrm{CO}_{2}$ emissions only. These follow historical emissions to presentday, followed by the $\mathrm{CO}_{2}$ component of the SRES A2 emissions scenario (as used in the C4MIP study; Friedlingstein et al., 2006). This matches the GCM simulation against which the IMOGEN "patterns" of climate change are calibrated, and thus its ability to replicate aspects of HadCM3LC may be considered. IMOGEN was run twice using the two

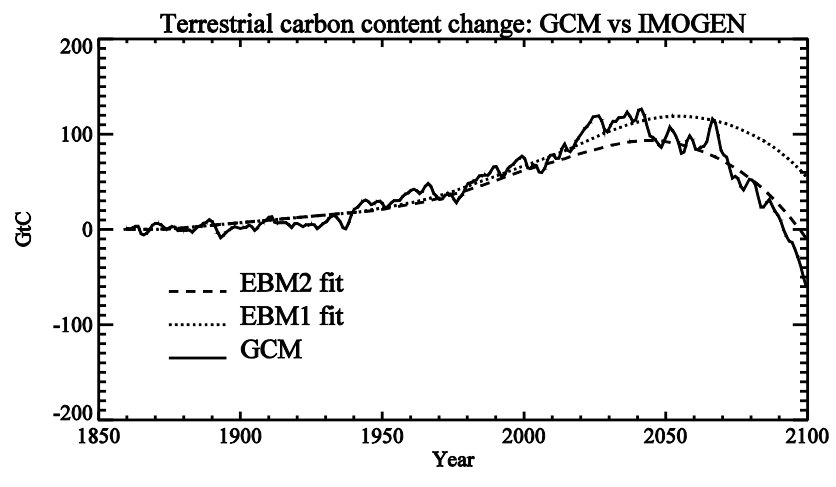

Fig. 3. IMOGEN EBM1 and EBM2 calculations (dotted and dashed lines, respectively) of change in total terrestrial carbon (both vegetation and soil, and across all land points except Antarctica) from 1860. Also plotted is the same quantity (continuous line) as predicted by HadCM3LC. As for Fig. 2 in all cases, the models are forced by the SRES A2 emissions scenario, but adopting only the carbon dioxide component (i.e. no non- $\mathrm{CO}_{2} \mathrm{GHGs}$ ).

configurations for the energy balance component (i.e. EBM1 and EBM2).

A main metric that we use to assess IMOGEN performance is its ability to model change in total terrestrial carbon content (i.e. carbon in vegetation and soils). This has important policy implications, influencing land-atmosphere fluxes of $\mathrm{CO}_{2}$ and thereby mitigating (or otherwise) anthropogenic $\mathrm{CO}_{2}$ emissions. In Fig. 3, both the GCM and two IMOGEN calculations (i.e. EBM1 and EBM2) of global terrestrial carbon are presented. Common to the GCM and both IMOGEN runs is the accumulation of carbon by the vegetation and soil for the period between pre-industrial times and present (i.e. a positive change in terrestrial carbon content since 1860). That is, the land surface is modelled as mitigating anthropogenic emissions of $\mathrm{CO}_{2}$, in keeping with the established view. All three models then continue to "drawdown" $\mathrm{CO}_{2}$ until the middle of the 21st Century, after which a change occurs, and the land surface becomes a net source. However, at around the year 2030 the two IMOGEN runs diverge markedly. Net losses of terrestrial carbon predicted by both the GCM and the EBM2 configuration of IMOGEN after 2060 are sufficiently large that by year 2100 the terrestrial carbon content will actually be less than that for preindustrial periods, with a slightly bigger loss for the GCM (this is similar behaviour to the prediction of Cox et al., 2000). In contrast the EBM1 configuration of IMOGEN fails to reproduce this change, maintaining much of the carbon gained in the early 21 st Century "draw-down". The result is striking as the two models differ only marginally in their configuration (Sect. 2.2). The larger climate sensitivity in the EBM2 configuration of IMOGEN is only around $0.3 \mathrm{~K}$ greater than that in the EBM1 configuration (i.e. $3.72 \mathrm{~K}$ versus $3.43 \mathrm{~K}$ respectively), and yet accounts for $70 \mathrm{Gt}$ Carbon difference in projected terrestrial carbon store by 2100 . To 
Table 1. Changes in total terrestrial carbon content, net primary productivity and runoff, relative to year 1860 and for four SRES scenarios, and all using EBM2. The year 1860 values are presented in the second column. Changes for period 1860 to 2100 are also expressed as percentages (in brackets). In addition, the change since year 1860 in atmospheric carbon and carbon sequestered by the ocean are also given (both in units of GtC, and positive numbers implying a gain).

\begin{tabular}{llllll}
\hline Variable & \multirow{2}{*}{ Year 1860 } & \multicolumn{4}{c}{ Change in 2100 } \\
\cline { 3 - 5 } & & SRES A1Fi & SRES A2 & SRES B1 & SRES B2 \\
\hline Terrestrial carbon $(\mathrm{GtC})$ & \multirow{2}{*}{1871} & -53 & -7 & 40 & 45 \\
& & $(-2.8 \%)$ & $(-0.4 \%)$ & $(2.1 \%)$ & $(2.4 \%)$ \\
$\mathrm{NPP}\left(\mathrm{GtC} \mathrm{yr}^{-1}\right)$ & \multirow{2}{*}{70.9} & +32.7 & +33.0 & +24.5 & +27.6 \\
& & $(46.1 \%)$ & $(46.5 \%)$ & $(34.6 \%)$ & $(38.9 \%)$ \\
Runoff $\left(10^{12} \mathrm{~m}^{3} \mathrm{yr}^{-1}\right)$ & \multirow{2}{*}{36.2} & +10.6 & +7.6 & +0.1 & +1.5 \\
& & $(29.3 \%)$ & $(20.0 \%)$ & $(0.3 \%)$ & $(4.1 \%)$ \\
\hline Change in atmospheric carbon $(\mathrm{GtC})$ & & +1964 & +1642 & +826 & +984 \\
Change in oceanic carbon $(\mathrm{GtC})$ & & +549 & +509 & +402 & +415 \\
\hline
\end{tabular}

put this into context, the accepted likely range in climate sensitivity in the recent IPCC assessment was $1.5-4.5 \mathrm{~K}$.

It is the "warmer" EBM2 configuration which reproduces the GCM's land surface sink to source behaviour, rather than the configuration which optimally fitted the GCM temperature response (EBM1). This highlights that there remain IMOGEN deficiencies if it is regarded as an emulator of HadCM3LC, as opposed to simply a credible model of climate change. Potential causes of this are discussed below.

The EBM2 IMOGEN configuration is extrapolated to three additional simulations, for SRES marker scenarios A1FI, B1 and B2 (but again, just adopting the $\mathrm{CO}_{2}$-only component of the emissions scenarios). The impact on total terrestrial carbon content is presented in Fig. 4. As expected for the more severe SRES A1FI scenario (i.e. higher emissions), the changes predicted in terrestrial carbon content are larger, with values for year 2100 indicating a massive loss of carbon back into the atmosphere. Quantities of Net Primary Productivity (NPP) and runoff are also diagnosed, these being fluxes related to the carbon cycle and the hydrological cycle respectively. For all four SRES simulations considered, Table 1 gives the global calculated values for these variables (also presented is terrestrial carbon content) for year 1860, and the change, for period 1860 to 2100 . For all simulations, global NPP increases by 2100 . However by this time, in all simulations, terrestrial carbon content is decreasing and hence the magnitude of soil respiration is increasing at an even faster rate, to overtake that of NPP. Hence the land surface is a net source of $\mathrm{CO}_{2}$. In addition, from Table 1, global runoff increases in all model simulations. This can be related to the analysis by Gedney et al. (2006) and Betts et al. (2007), suggesting that $\mathrm{CO}_{2}$-induced stomatal closure might be one factor contributing to the known increasing levels of runoff.

IMOGEN has been designed specifically as a tool to model climate change impacts on the land-surface, and thereby

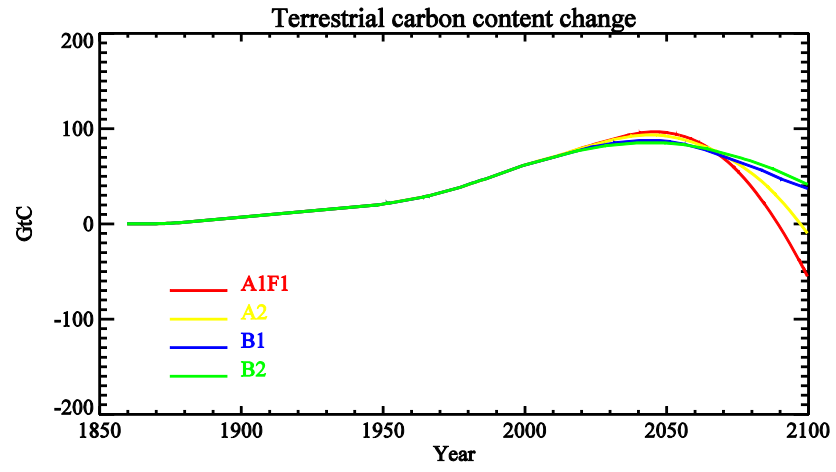

Fig. 4. IMOGEN EBM2 calculation of change in total terrestrial carbon from 1860 (both vegetation and soil, and across all land points except Antarctica) and for four SRES scenarios (but for the $\mathrm{CO}_{2}$-only component, i.e. no non- $\mathrm{CO}_{2} \mathrm{GHGs}$ ).

retains geographical complexity to allow regional impacts assessments. In Fig. 5 we present maps of NPP, terrestrial carbon content and runoff, all for the SRES A2 simulation using EBM2 parameterisation. The left hand panels are for the pre-industrial state (year 1860), whilst the right hand panels are the predicted changes between years 1860 and 2100 . Changes in net primary productivity can be used to infer future ecosystem vulnerability and indeed may be indicative of the geographical response of crop yields to future climate change. Regional patterns of land carbon sequestration can inform policy makers on the potential service ecosystems provide in absorbing anthropogenic $\mathrm{CO}_{2}$, and thus their ability to mitigate future climate change. Trends in runoff aid in understanding how the land hydrological cycle might evolve in response to climate change, affecting future water availability and security. 

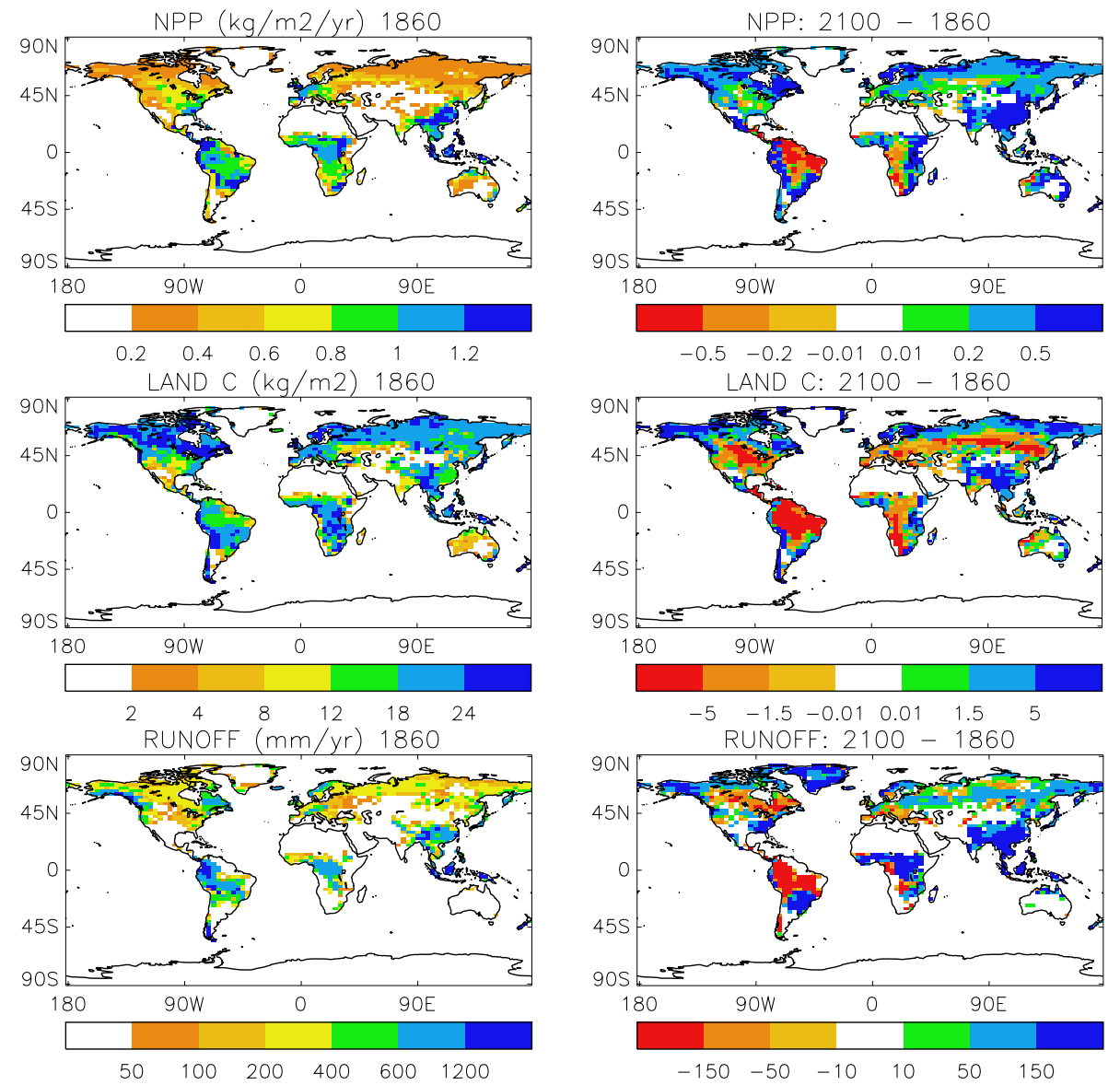

Fig. 5. Predictions of Net Primary Productivity, terrestrial carbon content (soil and vegetation) and runoff for year 1860, the start of the IMOGEN transient simulation (left hand panels). These values are considered representative of pre-industrial state. The right hand panels show the changes in each of these quantities during the period 1860 to 2100 . These simulations all correspond to the SRES A2 (CO 2 emissions only) scenario, and with the EBM2 configuration of IMOGEN.

\section{Discussion and conclusions}

The IMOGEN impacts modelling system is designed to predict surface climate and associated land surface impacts for future varying levels of atmospheric greenhouse gas concentrations for which GCM simulations may be unavailable. The system also allows rapid assessment of the consequences of changing the depiction of processes in the land surface scheme. This can be either through re-parameterisation of the existing model equations, or the inclusion of new land surface processes believed to have potential importance in a changing climate. In addition IMOGEN can be configured so that it is forced by known global observed climatologies, to which the analogue model predictions of future climate change can be added. In those circumstances the climate model against which the patterns have been fitted provides anomalies only, and thus removal of possible GCM biases.

The case study we present highlights how relatively small differences in modelled climate sensitivity cause large differences in predictions of land surface-to-atmosphere carbon flux at the end of the Century (for a "business-as-usual" emissions scenario). This overall sensitivity depends predominantly on the spatially-integrated balances between plant $\mathrm{CO}_{2}$ fertilisation and temperature influences on both plant physiology and on plant and soil respirations. Reducing uncertainties surrounding this balance are clearly important, as it will indicate the amount to which society can rely on terrestrial ecosystems to "draw down" emitted carbon dioxide.

There remain some caveats regarding IMOGEN use. At present it does not capture inter-annual variability, or intraannual variability that may occur in addition to current modelled mean seasonal changes. A future project may be to describe this through developing some form of additional pattern of statistical variability. Particular investigation is required to understand why the optimal parameterisation of the thermal components (EBM1) does not give the best fit to changes in terrestrial carbon store - a "warmer" parameterisation (e.g. EBM2) is required. A possible contribution to this difference is that the land surface is more sensitive to warmer years or seasons than the cooler years and 
seasons, and this can be investigated once GCM variability is captured. In addition, a more realistic "weather generator" is needed for describing the sub-daily timescales and characteristics of GCM-predicted surface climatology. The sub-daily variability may also influence, through the temporal aggregation, the EBM parameterisation required to mimic the GCM. A particular request is, therefore, that GCM modelling groups save high temporal resolution data - possibly at each timestep - for calibration of weather-generator components of impacts models. This does have huge data storage implications but in the first instance it may be necessary to record such diagnostics only for particular years, corresponding to different levels of global warming. As more GCM data becomes available the pattern-scaling concept, although known to be broadly valid (Huntingford and Cox, 2000), can be revisited and analyzed specifically for key geographical regions of interest. One further difference is the current methodology for forcing MOSES/TRIFFID with atmospheric data. In the GCM, the atmospheric data driving the land surface sub-model comes from the first atmospheric GCM model level, whereas in IMOGEN the $1.5 \mathrm{~m}$ temperature and humidity and $10 \mathrm{~m}$ wind speed are used. This is because these are the usual GCM diagnostics, in keeping with traditional meteorological measurement heights. Despite correcting for this difference in height, these differences in forcing the surface scheme lead to small perturbations within the heat and moisture fluxes that could integrate to give larger changes through the length of the integration. This could also generate differences between the modelled terrestrial carbon cycle in the GCM and in IMOGEN.

An additional limitation of the IMOGEN concept is that it fails to model the influence of local land-atmosphere energyand water-feedbacks on surface climate. Hence, for a radically different parameterisation of MOSES/TRIFFID (for instance, that alters significantly the timing of predicted Amazon "die-back"), an incompatibility might emerge between GCM analogue model estimates of near-surface temperature and humidity, and what would be predicted by the GCM should simulations with the revised land surface model be available. Work is now starting to consider adding a secondorder scaling pattern that depends explicitly on changes in land surface quantities. Finally the pattern-scaling concept for surface climate will be rigorously tested for long stabilisation scenarios (possibly going significantly beyond modelled year 2100), or even the emerging concept of climate "overshoot" (e.g. Huntingford and Lowe, 2007; Lowe et al., 2009), as GCM simulations become available depicting such futures.

Despite the issues raised above, all of which will be addressed as future refinements to the IMOGEN modelling structure, it is believed that this system can provide acceptable regional estimates of the impacts of climate change on the land surface. It can compute impacts issues of concern (i.e. related to food and water security) for a range of emission scenarios relatively quickly, and for any enhancements to modelled ecosystem response. This system allows "what if" type impacts questions to be readily answered as they emerge from international negotiations regarding future levels of atmospheric greenhouse gas concentrations. It has the potential to determine the main expected atmospheric drivers of change to ecosystem behaviour by individually switching patterns on and off for the various constituents of surface meteorology. Finally it opens many new scientific applications, through determining the global implications of new process understanding as this is added to models of the land surface.

Acknowledgements. $\mathrm{CH}$ and LMM recognise the support of the Centre for Ecology and Hydrology Science Budget fund. The Met Office authors were supported by the Joint DECC and Defra Integrated Climate Programme - DECC/Defra (GA01101).

Edited by: D. Lawrence

\section{References}

Betts, R. A., Boucher, O., Collins, M., et al.: Projected increase in continental runoff due to plant responses to increasing carbon dioxide, Nature, 448, 1037-1041, 2007.

Cox, P. M.: Description of the TRIFFID dynamic global vegetation model, Technical Note 24, Hadley Centre, Met Office, UK, 2001.

Cox, P. M., Betts, R. A., Bunton, C. B., Essery, R. L. H., Rowntree, P. R., and Smith, J.: The impact of new land surface physics on the GCM simulation of climate and climate sensitivity, Clim. Dynam., 15, 183-203, 1999.

Cox, P. M., Betts, R. A., Jones, C. D., Spall, S. A., and Totterdell, I. J.: Acceleration of global warming due to carbon-cycle feedbacks in a coupled climate model, Nature, 408, 184-187, 2000.

Cox, P. M., Huntingford, C., and Harding, R. J.: A canopy conductance and photosynthesis model for use in a GCM land surface scheme, J. Hydrol., 212-213, 79-94, 1998.

Fisher, R., McDowell, N., Purves, D., Moorcroft, P., Sitch, S., Cox, P., Huntingford, C., Meir, P., and Woodward, F. I.: Assessing uncertainties in a second-generation dynamic vegetation model caused by ecological scale limitations, New Phytol., 187, 666681, 2010.

Friedlingstein, P., Cox, P., Betts, R., et al.: Climate-carbon cycle feedback analysis: Results from the (CMIP)-M-4 model intercomparison, J. Climate, 19, 3337-3353, 2006.

Gedney, N., Cox, P. M., Betts, R. A., Boucher, O., Huntingford, C., and Stott, P. A.: Detection of a direct carbon dioxide effect in continental river runoff records, Nature, 439, 835-838, 2006.

Gedney, N., Cox, P. M., and Huntingford, C.: Climate feedback from wetland methane emissions, Geophys. Res. Lett., 31, L20503, doi:10.1029/2004GL020919, 2004.

Gordon, C., Cooper, C., Senior, C., Banks, H., Gregory, J., Johns, T., Mitchell, J., and Wood, R.: The simulation of SST, sea ice extents and ocean heat transport in a version of the Hadley Centre coupled model without flux adjustments, Clim. Dynam., 16, 147-168, 2000.

Houghton, J. T., Callander, B. A., and Varney, S. K.: Climate Change 1992: The Supplementary Report to the IPCC Scientific Assessment, Cambridge University Press, Cambridge, UK, 200 pp., 1992. 
Hughes, J. K., Lloyd, A. J., Huntingford, C., Finch, J. W., and Harding, R. J.: The impacts of extensive planting of Miscanthus as an energy crop on future $\mathrm{CO}_{2}$ atmospheric concentrations, Global Change Biol. Bioenerg., 2, 79-88, 2010.

Huntingford, C. and Cox, P. M.: An analogue model to derive additional climate change scenarios from existing GCM simulations, Clim. Dynam., 16, 575-586, 2000.

Huntingford, C., Fisher, R. A., Mercado, L., et al.: Towards quantifying uncertainty in predictions of Amazon "Die-back",Philos. T. Roy. Soc. B, 363, 1857-1864, 2008.

Huntingford, C., Harris, P. P., Gedney, N., Cox, P. M., Betts, R. A., Marengo, J. A., and Gash, J. H. C.: Using a GCM analogue model to investigate the potential for Amazonian forest dieback, Theor. Appl. Climatol., 78, 177-185, 2004.

Huntingford, C. and Lowe, J.: Overshoot scenarios and climate change, Science, 316, 829, 2007.

Imhoff, M. L., Bounoua, L., Ricketts, T., Loucks, C., Harriss, R., and Lawrence, W. T.: Global patterns in human consumption of net primary production, Nature, 429, 870-873, 2004.

IPCC: Climate Change 2007: The Physical Science Basis, Contribution of Working Group I to the Fourth Assessment Report of the Intergovernmental Panel on Climate Change, edited by: Solomon, S., Qin, D., Manning, M., Chen, Z., Marquis, M., Averyt, K. B., Tignor, M., and Miller, H. L., Cambridge University Press, Cambridge, UK and New York, NY, USA, 996 pp., 2007.

Jones, C. D., Cox, P. M., and Huntingford, C.: Climate-carbon cycle feedbacks under stabilization: uncertainty and observational constraints, Tellus B, 58, 603-613, 2006.

Joos, F., Bruno, M., Fink, R., Siegenthaler, U., and Stocker, T. F.: An efficient and accurate representation of complex oceanic and biospheric models of anthropogenic carbon uptake, Tellus B, 48, 397-417, 1996.

Lobell, D. B. and Field, C. B.: Global scale climate-crop yield relationships and the impacts of recent warming, Environ. Res. Lett., 2, 014002, doi:10.1088/1748-9326/2/1/014002, 2007.
Lowe, J. A., Huntingford, C., Raper, S. C. B., Jones, C. D., Liddicoat, S. K., and Gohar, L. K.: How difficult is it to recover from dangerous levels of global warming?, Environ. Res. Lett., 4, 014012, doi:10.1088/1748-9326/4/1/014012, 2009.

Mercado, L. M., Bellouin, N., Sitch, S., Boucher, O., Huntingford, C., Wild, M., and Cox, P. M.: Impact of changes in diffuse radiation on the global land carbon sink, Nature, 458, 1014-1017, 2009.

Moorcroft, P. R., Hurtt, G. C., and Pacala, S. W.: A method for scaling vegetation dynamics: the ecosystem demography model (ED), Ecol. Monogr., 71, 557-586, 2001.

Moss, R. H., Edmonds, J. A., Hibbard, K. A., Manning, M. R., Rose, S. K., van Vuuren, D. P., Carter, T. R., Emori, S., Kainuma, M., Kram, T., Meehl, G. A., Mitchell, J. B. F., Nakicenovic, N., Riahi, K., Smith, S. J., Stouffer, R. J., Thomson, A. M., Weyant, J. P., and Wilbanks, T. J.: The next generation of scenarios for climate research and assessment, Nature, 463, 747-756, 2010.

Nakiæenoviæ, N., Alcamo, J., Davis, G., et al.: IPCC Special Report on Emissions Scenarios, Cambridge University Press, Cambridge, UK, 570 pp., 2000.

New, M., Hulme, M., and Jones, P. D.: Representing twentieth century space-time climate variability, Part 1: development of a 1961-90 mean monthly terrestrial climatology, J. Climate, 12, 829-856, 1999.

Schröter, D., Cramer, W., Leemans, R., et al.: Ecosystem Service Supply and Vulnerability to Global Change in Europe, Science, 310, 1333-1337, 2005.

Sitch, S., Cox, P. M., Collins, W. J., and Huntingford, C.: Indirect radiative forcing of climate change through ozone effects on the land-carbon sink, Nature, 448, 791-794, 2007.

Sitch, S., Huntingford, C., Gedney, N., et al: Evaluation of the terrestrial carbon cycle, future plant geography and climate-carbon cycle feedbacks using five Dynamic Global Vegetation Models (DGVMs), Global Change Biol., 14, 2015-2039, 2008.

Sutton, R. T., Dong, B. W., and Gregory, J. M.: Land/sea warming ratio in response to climate change: IPCC AR4 model results and comparison with observations, Geophys. Res. Lett., 34, L02701, doi:10.1029/2006/GL028164, 2007. 